\title{
Coordinated diagnostic approach for adult obstructive lung disease in primary care
}

\author{
C.P. van Schayck ${ }^{a}$, Mark L. Levy ${ }^{b}$, Joyce C. Chen ${ }^{c}$, Sharon Isonakad, \\ R.J. Halbert ${ }^{\mathrm{d}, e, *}$
}

a Department of General Practice, Research Institute Caphri, University of Maastricht, Maastricht, The Netherlands

b Department of General Practice and Primary Care, University of Aberdeen, Aberdeen, UK

c Constella Health Strategies, Santa Monica, CA, USA

${ }^{d}$ Cerner Health Insights, 9100 Wilshire Blvd., Suite 955E, Beverly Hills, CA 90212, USA

e Department of Community Health Sciences, UCLA School of Public Health, Los Angeles, CA, USA

Received 11 March 2004; accepted 27 July 2004

\section{KEYWORDS \\ Diagnosis; \\ Obstructive Lung \\ Diseases; \\ Practice Guidelines; \\ Primary Health Care}

\section{Introduction}

Obstructive lung disease (OLD), including chronic obstructive pulmonary disease (COPD) and asthma,

\footnotetext{
* Corresponding author. Tel.: +1 310598 4462;

fax: +18169361862.

E-mail address: rhalbert@cerner.com (R.J. Halbert).
}

\begin{abstract}
Summary
Aims: To present an age-stratified approach to the diagnosis of obstructive lung disease based on asthma and COPD guidelines and epidemiology.

Methods: Asthma guidelines emphasize the role of the history and physical examination, with pulmonary function used primarily to confirm the diagnosis. COPD guidelines begin with symptoms and risk exposure, presenting spirometry as the primary diagnostic maneuver. Data from the National Health Interview Survey and the Third National Health and Nutrition Examination Survey illustrate relationships in prevalence of asthma and COPD in nationally representative samples.

Results: Asthma prevalence in adults declines with age from $5-10 \%$ at age $20-40$ to 4-8\% above age 60. COPD is uncommon in adults under age 40 but increases with age, surpassing asthma in older adults.

Conclusions: These trends suggest that asthma screening is most useful in adults up to age 40, after which COPD screening and differential diagnosis are of comparable or greater utility.

(c) 2004 General Practice Airways Group. Published by Elsevier Ltd. All rights reserved.
\end{abstract}

is among the most common conditions encountered in primary care. For both of these conditions, underdiagnosis continues to be a widespread problem [1]. Accurately distinguishing between asthma and COPD in persons who present with features of both diseases is recognized as a major diagnostic challenge [2]. To increase the recognition and appropriate treatment of OLD, a number of guidelines have 
been developed in recent years. However, there is currently no coordinated approach to the diagnosis of OLD in primary care. We now present an approach to diagnosis incorporating key elements from guidelines and epidemiological evidence.

\section{Guidelines for obstructive lung disease}

In diagnosing asthma, guidelines focus on periodicity of symptoms, airway narrowing (symptoms such as episodic breathlessness, wheezing, and chest tightness), and the presence of airway hyperresponsiveness. The evidence-based guidelines produced by the Global Initiative for Asthma (GINA) emphasize the importance of wheeze in diagnosing asthma [3]. These guidelines state that asthma can often be diagnosed on the basis of symptoms, with a supportive role for measurements of lung function particularly the presence of reversibility of lung function - in enhancing diagnostic confidence. As such, sections of the GINA guidelines are devoted to the role of the following measurements in the clinical diagnosis of asthma: physical examination, lung function measurements (i.e., spirometry, peak expiratory flow, and airway hyperresponsiveness), and measurements of markers of airway inflammation and allergic status.

In older adults, asthma diagnosis is complicated, in part, by the coexistence of COPD and the resulting overlap and confusion between the two diseases. The (US) National Asthma Education and Prevention Program, in acknowledging these particular difficulties, commissioned a working group on asthma in the elderly in 1992. This group issued a report highlighting special considerations for managing asthma in the elderly [4], particularly noting that incomplete reversibility becomes increasingly common in elderly patients, with some developing severe chronic airflow obstruction, and that this situation creates diagnostic confusion. The report also addressed the need to differentiate asthma from other conditions seen with increased frequency in older populations.

The Global Initiative for Obstructive Lung Disease (GOLD) provides a working definition of COPD focusing on "airflow limitation that is not fully reversible [5]." Furthermore, GOLD provides an operational definition for COPD based on spirometry: a ratio of postbronchodilator forced expiratory volume in one second $\left(\mathrm{FEV}_{1}\right)$ to forced vital capacity (FVC) less than 70\%. GOLD's focus on objectively measured airway obstruction is accompanied by a focus on the preeminence of smoking as a risk factor for COPD.
Thus, the GINA guidelines emphasize the role of the medical history and physical examination in the diagnosis of asthma, emphasizing the classic presentation of episodic dyspnea or chest tightness and findings of expiratory wheezes. Pulmonary function and additional studies are used primarily to confirm the diagnosis. GOLD, on the other hand, begins with symptoms (cough and sputum) and risk exposure (primarily cigarette smoking), but presents spirometry as the primary approach for identifying airway obstruction, providing standardized protocols for interpreting lung function tests. The tension between these two approaches does not always indicate a clear path for the primary care provider, who must evaluate patients with consideration of both diseases. The epidemiological evidence can provide some assistance.

\section{Epidemiology of obstructive lung disease}

Data from the National Health Interview Survey (NHIS) and the Third National Health and Nutrition Examination Survey (NHANES III), illustrate agespecific trends in asthma relative to COPD in adults using representative samples for the US population. Data from the NHIS show that the prevalence of self-reported asthma peaks in the 12-17 year old age group at $14.2 \%$ [6], drops to $9.2 \%$ among $18-44$ year olds, and continues to decrease gradually with age (Figure 1) [7]. At the same time, the prevalence of emphysema and chronic bronchitis begins a steady increase, starting from rates of $0.3 \%$ and $3.5 \%$ respectively, in 18-44 year olds.

Data from NHANES III (Figure 2) illustrate the rise in patient-reported COPD with-age [8,9]. Among adults aged 30-39 years, COPD is no more common than asthma. COPD prevalence rises steadily with age until, by age 60 and over, COPD is three times more common than asthma. When airway obstruction is considered independent of diagnostic label, the rise with age is even more pronounced [9].

Despite the limitations of these studies, the trends are clear - COPD is less common than asthma in younger adults, but surpasses asthma with increasing age. Differential diagnosis considerations also vary widely by age group. This suggests the need for tailored diagnostic approaches in relevant sub-groups, and, in fact, evidence-based asthma guidelines recognize that the elderly, pediatric, and occupational populations pose specific challenges in this regard. 


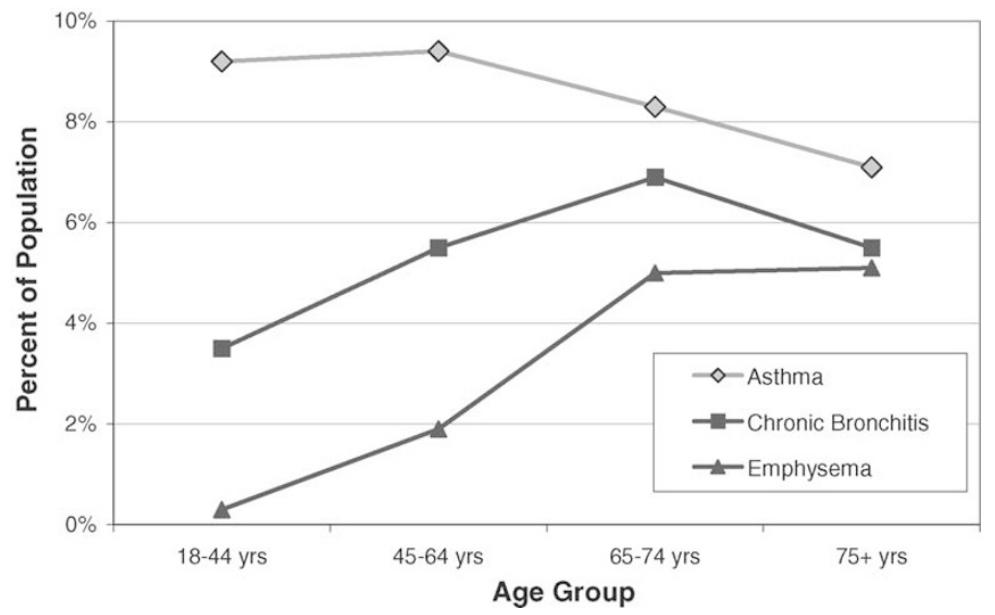

Figure 1 Prevalence of patient-reported asthma, chronic bronchitis, and emphysema, NHIS, 1998 [7].

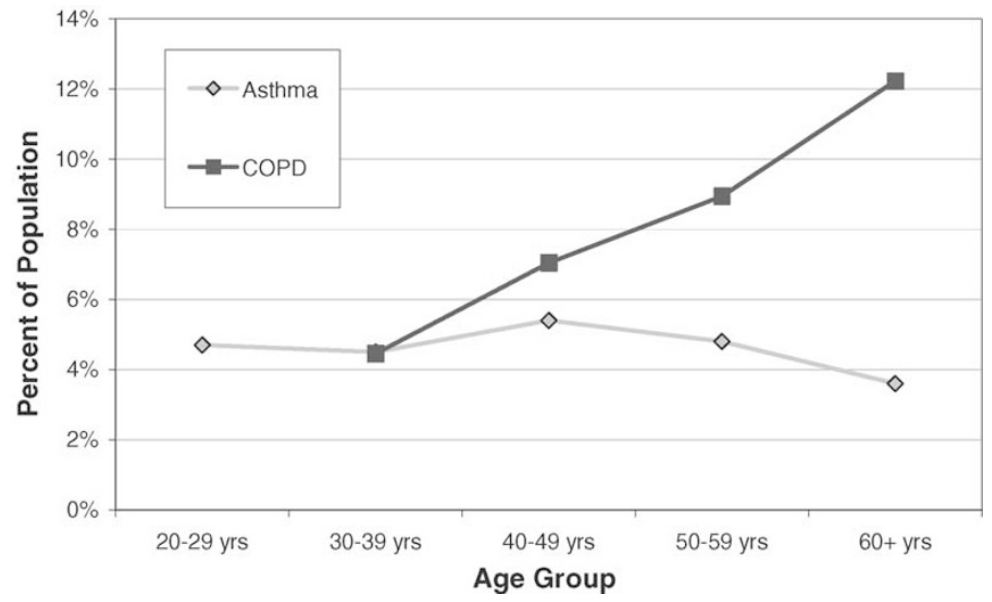

Figure 2 Prevalence of patient-reported asthma and COPD, NHANES III, 1988-1994 [8,9].

\section{Recommended approach}

A coordinated approach to differential diagnosis may be developed by incorporating key elements of evidence-based guidelines together with epidemiological evidence. Age trends suggest that asthma case-finding may prove to be of /greatf est utility in adults up to approximately age 40 or 45. Above that age range, the utility of casefinding for COPD would be comparable to or even exceed that for asthma, and differential diagnosis between the two diseases becomes increasingly important. Such an approach is summarized in Figure 3 .

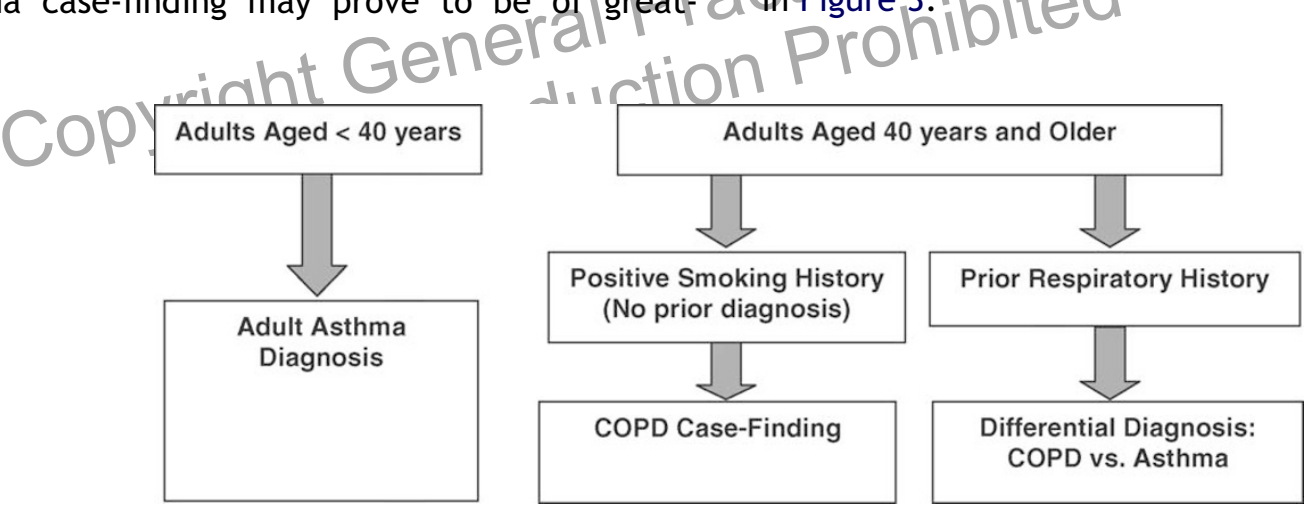

Figure 3 Coordinated diagnostic approach to patients with obstructive lung disease. 
Asthma diagnostic criteria and supporting literproach of symptoms and physical findings to confirm a diagnosis of asthma. This cluster of symptoms and physical findings is well recognized and accepted. Evidence-based guidelines provide ample guidance on the types of information to consider in conducting the clinical interview. However, the intermittent nature of these symptoms, together with the lack of reliance upon objective and easily reproducible measurements, requires the physician to utilize subjective assessments and historical data.

In adults aged 40 and over, two major diagnostic issues are prominent. Patients presenting with respiratory symptoms and a positive history of exposure to respiratory irritants are candidates for a COPD case-finding approach. For patients presenting with prior evidence of respiratory disease (for example, prior diagnosis of OLD, respiratory medications, frequent respiratory infections, etc.) an approach that focuses on differentiating COPD from asthma is more appropriate.

A new guideline for chronic respiratory disease, which is being developed by the International Primary Care Airways Group (IPAG), uses the approach described here [10]. In this document, guidelines developed by GINA, GOLD and 'Allergic Rhinitis and its Impact on Asthma' (ARIA) [11] are adapted for primary care. Simplified diagnostic tools are also included with the IPAG guideline, to help facilitate implementation in the busy primary care setting. These include validated tools for asthma diagnosis developed by the International Union Against Tuberculosis and Lung Disease [12,13] and the American Thoracic Society Division of Lung Diseases [14]. Similar tools are being developed to assist in identifying persons likely to have unrecognized COPD [15] and to help distinguish COPD from asthma [16]. The coordinated diagnostic algorithm presented here will facilitate systematic implementation of these tools in primary care. ature most commonly recommend a combined ap-

[2] van Schayck CP. Diagnosis of asthma and chronic obstructive pulmonary disease in general practice. $\mathrm{Br} \mathrm{J}$ Gen Pract 1996;46:193-7.

[3] Global Initiative for Asthma. National Heart, Lung, and Blood Institute/World Health Organization Workshop Report: Global Strategy for Asthma Management and Prevention. Updated 2003. National Institutes of Health, Bethesda, MD. NIH Publication No. 02-3659. Available at URL: http://www.ginasthma.com.

[4] National Asthma Education and Prevention Program Working Group on Asthma in the Elderly. Considerations for Diagnosing and Managing Asthma in the Elderly. National Institutes of Health Publication No. 02-3659. Bethesda, MD, 1996. Available at URL: http://www.nhlbi.nih.gov/ health/prof/lung/asthma/as_elder.pdf.

[5] Global Initiative for Chronic Obstructive Lung Disease. Global Strategy for the Diagnosis, Management, and Prevention of Chronic Obstructive Pulmonary Disease. National Institutes of Health, National Heart, Lung, and Blood Institute; April 2001 (Updated 2004). Available at URL: http: / / www.goldcopd.com.

[6] Blackwell DL, Tonthat L. Summary health statistics for U.S. Children: National Health Interview Survey, 1998. Vital Health Stat 2002;10(208):7. Available at URL: http://www.cdc.gov/nchs/data/series/sr_10/sr10_208.pdf.

[7] Pleis JR, Coles R. Summary health statistics for U.S. Adults: National Health Interview Survey, 1998. Vital Health Stat 2003;10(209):19. Available at URL: http:// www.cdc.gov/nchs/data/series/sr_10/sr10_209.pdf.

[8] Arif AA, Delclos GL, Lee ES, et al. Prevalence and risk factors of asthma and wheezing among US adults: an analysis of the NHANES III data. Eur Respir J 2003;21:82733.

[9] Celli BR, Halbert RJ, Isonaka S, Schau B. Population impact of different definitions of airway obstruction. Eur Respir $J$ 2003;22:268-73.

[10] International Primary Care Airways Group (IPAG). Chronic airways disease handbook: a guide for primary care physicians. Working draft, January 2004.

[11] Bousquet J, Van Cauwenberge P, Khaltaev N, ARIA Workshop Group. World Health Organization. Allergic rhinitis and its impact on asthma. J Allergy Clin Immunol 2001;108(5 Suppl):S147-334.

[12] Ravault C, Kauffmann F. Validity of the IUATLD (1986) questionnaire in the EGEA study. International Union Against Tuberculosis and Lung Disease. Epidemiological study on the Genetics and Environment of Asthma, bronchial hyperresponsiveness and atopy. Int J Tuberc Lung Dis 2001;5: 191-6.

[13] Sistek D, Tschopp JM, Schindler C, et al. Clinical diagnosis of current asthma: predictive value of respiratory symptoms in the SAPALDIA study. Swiss Study on Air Pollution and Lung Diseases in Adults. Eur Respir J 2001;17:214-9.

[14] Ferris BG. Epidemiology Standardization Project (American Thoracic Society). Am Rev Respir Dis 1978;118:1120.

[15] Price D, Tinkelman D, Nordyke RJ, et al. Utility of a symptom-based questionnaire for identifying COPD in smokers [abstract]. Am J Respir Crit Care Med 2004;169(7 Suppl):A605.

\section{References}

[1] van Weel C. Underdiagnosis of asthma and COPD: is the general practitioner to blame? Monaldi Arch Chest Dis 2002;57:65-8.
[16] Tinkelman D, Price D, Nordyke RJ, et al. Questionnaire for differential diagnosis of obstructive lung disease [abstract]. Eur Respir J 2004;24(Suppl 48):473s. 